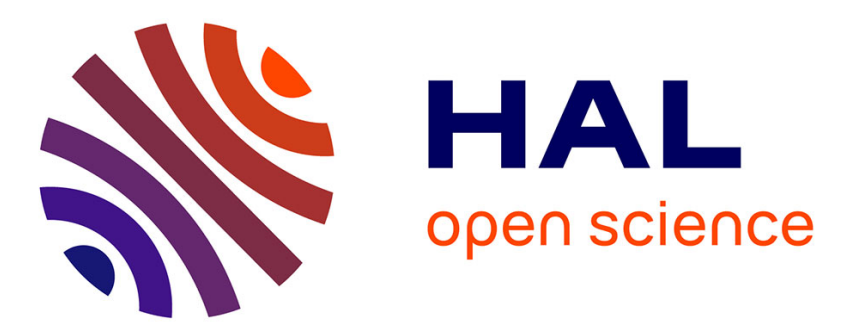

\title{
Treatment of Textile Waste Waters by Hydroxyapatite Co-Precipitation with Adsorbent Regeneration and Reuse
}

\author{
W. Lemlikchi, P. Sharrock, M. O. Mecherri, M. Fiallo, Ange Nzihou
}

\section{- To cite this version:}

W. Lemlikchi, P. Sharrock, M. O. Mecherri, M. Fiallo, Ange Nzihou. Treatment of Textile Waste Waters by Hydroxyapatite Co-Precipitation with Adsorbent Regeneration and Reuse. Waste and Biomass Valorization, 2012, 3 (1), pp.75-79. 10.1007/s12649-011-9096-0 . hal-01632408

\section{HAL Id: hal-01632408 https://hal.science/hal-01632408}

Submitted on 16 Jan 2019

HAL is a multi-disciplinary open access archive for the deposit and dissemination of scientific research documents, whether they are published or not. The documents may come from teaching and research institutions in France or abroad, or from public or private research centers.
L'archive ouverte pluridisciplinaire HAL, est destinée au dépôt et à la diffusion de documents scientifiques de niveau recherche, publiés ou non, émanant des établissements d'enseignement et de recherche français ou étrangers, des laboratoires publics ou privés. 


\title{
Treatment of Textile Waste Waters by Hydroxyapatite Co-Precipitation with Adsorbent Regeneration and Reuse
}

\author{
W. Lemlikchi • P. Sharrock • M. O. Mecherri • \\ M. Fiallo $\cdot$ A. Nzihou
}

\begin{abstract}
When dissolved calcium salts are reacted in aqueous medium in the presence of phosphate anions, a gelatinous precipitate forms. Maturation of this precipitate eventually leads to the formation of hydroxyapatites (HA). HA is a stable solid with high specific surface area, and interesting adsorption properties. Thermal treatment at $800^{\circ} \mathrm{C}$ eliminates adsorbed organic matter and generates crystalline HA. Such HA can be recovered and reused by dissolution in acidic water. We have experimented with recycled HA the co-precipitation of textile dyes, and found that HA can be reused many times without loss of activity. However, in the case of blue dyes containing cupric ions, the metal ions remain in the solid phase following calcinations and the reactivity decreases slightly. In most cases, a very high level of dye removal was observed (above $98 \%$ ), with little loss of recycled HA (12\%). This makes the dye remediation process by HA co-precipitation economical and durable. Laboratory tests with a real industrial effluent showed a linear relationship between absorbance
\end{abstract}

W. Lemlikchi · M. O. Mecherri

Laboratoire LCAGC,

Université Mouloud Mammeri,

Tizi-Ouzou 15000, Algérie

e-mail:w.lemlikchi@gmail.com

M. O. Mecherri

e-mail: mecherri@gmail.com

P. Sharrock $(\bowtie) \cdot$ M. Fiallo

Laboratoire SIMAD, Université Paul Sabatier,

31062 Toulouse, France

e-mail: patrick.sharrock@iut-tlse3.fr

\section{A. Nzihou}

Centre RAPSODEE, CNRS, Université de Toulouse,

Ecole des Mines Albi, Campus Jarland, 81013 Albi, France abatement and introduced calcium concentration, indicating the feasibility of the process.

Keywords Dye removal $\cdot$ Hydroxyapatite $\cdot$ Adsorbent regeneration - Elimination rate

\section{Introduction}

The current problem with polluted industrial waters in developing nations is the absence of treatment prior to environmental discharge, combined with the formation of large amounts of wastes when treatment is processed. Indeed, whether the treatment method uses chemical, biological or electrical means, large amounts of sludges are produced which are difficult to handle and dispose of [1]. It is of obvious interest to develop economical dye removal processes which do not result in waste displacement from liquid to solid phases difficult to manage. Adsorption is a simple purification technique that is often applied with inexpensive adsorbents in order to clarify waste waters [2]. Thereafter, organic solids can sometimes be composted or burned [3-8], whereas mineral adsorbents are usually disposed of in landfills [9]. It was the aim of this research to evaluate the possibility of using HA calcium phosphates as adsorbents to purify textile dye waste waters $[10,11]$ and investigate the valorization of the mineral phase of the waste following a thermal treatment to regenerate the mineral adsorbent [1]. Another motivation lies in the fact that water treatment with HA precipitation occurs near neutral $\mathrm{pH}$ values, thus allowing the treated water to be returned to the environment without further $\mathrm{pH}$ adjustment. Furthermore, HA is not an environmentally dangerous product, and is commonly found in soils as phosphate rock. HA forms rapidly upon mixing calcium and phosphate ions 
at or above neutral $\mathrm{pH}$ values, and has a low solubility product.

\section{Experimental}

The textile dye characteristics are presented in Table 1. Synthetic dye solutions were made by dissolution in distilled water at a concentration of $50 \mathrm{mg} / \mathrm{L}$ (typical for wastewater), and HA solutions were made by adding concentrated $\mathrm{HCl}$ to a suspension of $100 \mathrm{mg} \mathrm{HA}$ powder in $100 \mathrm{~mL}$ of distilled water until the $\mathrm{pH}$ value reached 2. A genuine waste water effluent was collected at Bercolor, a textile dying company located in Roquecourbe, France, which uses many different dyes and processes them in an in-house biological waste water treatment plant. The samples were collected at the entrance of the waste water flow in 11 air-tight plastic bottles and tested immediately within $24 \mathrm{~h}$ after sampling.

Batch treatments were carried out at room temperature in air by mixing $100 \mathrm{~mL}$ of synthetic dye solutions with the chosen amount of HA solution, re-adjusting the $\mathrm{pH}$ value to 8 , and stirring for $5 \mathrm{~min}$ at $120 \mathrm{rpm}$ followed by decantation during $15 \mathrm{~min}$ or $6 \mathrm{~h}$. The solids were recovered from the decanted suspensions by filtration at atmospheric pressure on Whatman filter papers, followed by drying at room temperature overnight. The collected solids were then heated to $800^{\circ} \mathrm{C}$ for a $10 \mathrm{~min}$ period inside a tubular 21100 Thermolyne furnace in open air crucibles, at the maximum heating rate (30 min from room to max temperature). The cooled solids were recovered and weighed on a Sartorius balance to a precision of $0.1 \mathrm{mg}$.

Repeat experiments were made with the recovered HA solids re-dissolved in dilute $\mathrm{HCl}$ and contacted with the same amounts of dye solutions to obtain identical dye/ adsorbent ratios. This was carried out on five consecutive runs, and the dye removal was measured at each step as well as the \% recovery of HA after heat treatment. Further trials were conducted by keeping the same amount of dyes and reusing the recovered HA in decreasing amounts. The dye to adsorbent ratios then increased progressively. In each case, the dye removal efficiencies were measured by UV-Vis spectroscopy of filtered solutions using a Perkin-
Elmer Lambda2 spectrometer with $1 \mathrm{~cm}$ path length quartz cells and correcting for dilution when necessary.

In the case of the large HA/dye ratio tested, the constant mass ratio used was 20 and the decantation times were 15 min. Two dyes were used (BH and RD) and the results expressed as average value with calculated standard deviation.

For the industrial waste water tests, the absorbance was measured at $580 \mathrm{~nm}$ and the decrease was measured as a function of the amount of calcium introduced to form a calcium phosphate precipitate with $\mathrm{Ca} / \mathrm{P}$ ratio of 1.7 . The $\mathrm{pH}$ was adjusted to be between the values of 7 and 8 before mixing for $15 \mathrm{~min}$ followed by filtration as done for the synthetic dye solutions. No action was taken to modify the industrial waste-water by removing any of the additives used in the industrial dying process.

\section{Results and Discussion}

When the $\mathrm{pH}$ of dye containing solutions was adjusted to $\mathrm{pH}=8$, and in the presence of calcium and phosphate ions, a precipitate formed rapidly which decolorized the solutions. Following filtration, the remaining absorbance allowed to calculate the amount of dye removal. Normally, pure HA is a white solid, but in the presence of dyes, the HA precipitates were colored. Thermal analysis revealed that a weight loss between 14 and $15 \%$ of the dried weight occurred between 120 and $180^{\circ} \mathrm{C}$, attributed to water loss. The next heating step to $800^{\circ} \mathrm{C}$ caused a weight loss between 30 and $33 \%$ of the initial dry mass, and was attributed to organic matter combustion. As illustrated in Fig. 1, the mass loss was higher for the first calcination (33\%) than for the fourth $(30 \%)$. This means that on the first use, the HA adsorbed $3 \%$ more dye than on the fourth use.

An excess of HA with respect to the dye concentration (mass of HA precipitated $>$ mass of dye in solution) resulted in a better clarification of the water. Following the thermal treatment, the recovered HA consisted in a white powder with an infrared spectrum typical of HA. Because at this temperature HA was not sintered, it could be easily dissolved in dilute $\mathrm{HCl}$, for reuse in another co-precipitation stage with another batch of dyed water. The consecutive results obtained are presented in Table 2.

Table 1 Characteristics of the dyes used

\begin{tabular}{llll}
\hline Abbreviations & Commercial name & C.I. name & $\lambda_{\max }(\mathrm{nm})$ \\
\hline DR & Dianix red HBSL & Red disperse 167 & 460 \\
AR & Alizarine red S & Mordant red 3 & $420(\mathrm{pH}=2)$ \\
HB & Hydron blue R & Vat blue 43 & 600 \\
TB & Turquoise blue PG R & Reactive blue 72 & 662 \\
ST & Solophenyl turquoise BRLE & Direct blue 199 & 605 \\
CB & Cibacron blue P 3R & Reactive blue 49 & 587 \\
\hline
\end{tabular}




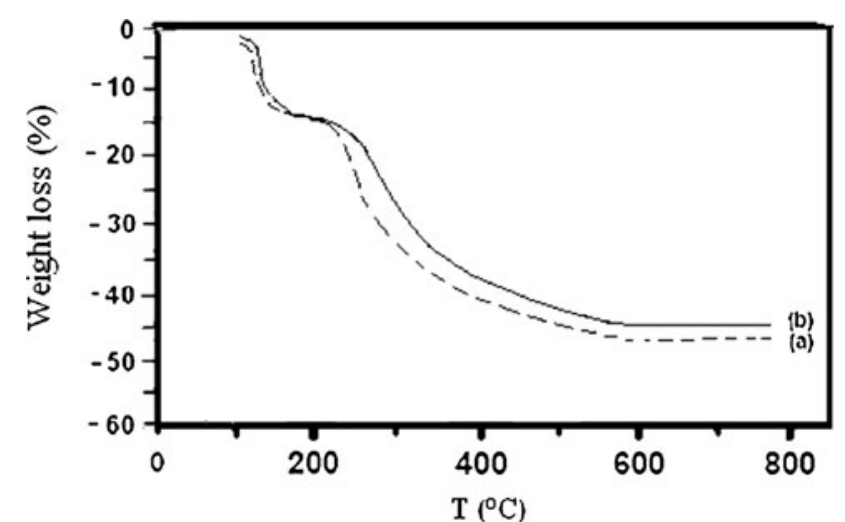

Fig. 1 Thermogravimetric curves of dye DR after 1st and 4th calcination $\left(\mathrm{r}_{\mathrm{m}}=2\right)$. $a$ 1st calcination; weight loss $(\%)=33 ; b$ th calcination; weight loss $(\%)=30$

On the average, about $85 \%$ of spent adsorbent was recovered as calcined HA in the case of textile dyes, while $78 \%$ was recovered for Alizarin AR after the 1st calcination. After the 2nd calcination, the recovery yields were respectively 78 and $30 \%$ for dyes and alizarin red. Following the 3 rd calcination, the HA/dye ratios decreased to 2. The loss of adsorbent as a function of trial numbers is illustrated in Fig. 2. The color abatement diminished progressively after each trial (Fig. 3).

It can be seen that the dye adsorption capacities are good for most dyes (between 70 and 99\% elimination) except for $\mathrm{CB}$ which is only slightly eliminated from solution (from 18 to $7 \%$ ). The removal capacities remain similar for most dyes, except for the copper containing ST dye where the abatement drops from $94 \%$ in the first step to $75 \%$ on the fourth re-use. This can be related to the fact that copper is not eliminated by the thermal treatment and remains in the
HA solids thereby modifying the adsorption properties. It is notable that even with low adsorbent/dye ratios below 2, the dye removal is performing well ( $97 \%$ elimination for DR dye and $99 \%$ elimination for HB dye).

The losses in recovered HA can be attributed to two factors which are experimental physical loses during filtration, drying and thermal treatment steps, and solubility losses caused by incomplete precipitation due to limited but small solubility of HA, particularly in the presence of dyes which tend to slow the HA precipitation process. This is why the losses became more important when smaller amounts of HA were available. Clearly, the HA adsorbent loss increased as the amount of adsorbent diminished.

To gain more insight into the influence of the adsorbent /dye ratio effects, further experiments were carried out with predetermined ratios at longer time periods $(6 \mathrm{~h})$ to allow for more complete precipitation. Results, presented in Table 3 , show that nearly complete dye removal could be achieved by waiting $6 \mathrm{~h}$ for complete co-precipitation, and that color abatement increased when more adsorbent was used.

Correspondingly, the amount of solids lost decreased when more was used. The best results were obtained when the weight of HA adsorbent was five times the amount of dye weight present in solution. From these results, it can be appreciated that HA works well for most cases except for the CB (Cibacron Blue) dye.

The fact that some HA is lost due to dissolution in water should be uneventful in the environment for lack of toxicity of calcium and small amounts of phosphate. The strong adsorption of some dyes on the HA precipitates can be explained by strong interaction between phenolic groups in the organic molecules and the calcium ions. This is
Table 2 Percentage of HA recovered following coprecipitation with various dyes at different adsorbent/dye ratios $\left(\mathrm{r}_{\mathrm{m}}\right)$ in consecutive experiments using recycled $\mathrm{HA}$

The dye removal efficiencies are indicated

\begin{tabular}{lcccccc}
\hline Dyes & AR & DR & TB & HB & ST & CB \\
\hline 1st calcination $\left(\mathrm{r}_{\mathrm{m}}=5\right)$ & & & & & & \\
$\quad \mathrm{r}_{\mathrm{m}}$ (mg of HA $/ \mathrm{mg}$ of dyes) & 5.0 & 5.0 & 5.0 & 5.0 & 5.0 & 5.0 \\
\% HA recovered & 78.30 & 87.20 & 82.00 & 84.80 & 79.20 & 84.10 \\
\% Dye elimination & 98.96 & 99.34 & 73.38 & 99.90 & 93.95 & 18.73 \\
2nd calcination $\left(\mathrm{r}_{\mathrm{m}} \sim 4\right)$ & & & & & & \\
$\mathrm{r}_{\mathrm{m} \text { (mg of HA } / \mathrm{mg} \text { of dyes) }}$ & 3.9 & 4.4 & 4.1 & 4.2 & 4.0 & 4.2 \\
\% HA recovered & 29.50 & 78.10 & 78.00 & 78.80 & 84.60 & 78.60 \\
\% Dye elimination & 89.51 & 98.94 & 37.14 & 98.93 & 80.30 & 12.03 \\
3rd calcination $\left(\mathrm{r}_{\mathrm{m}} \sim 3\right)$ & & & & & & \\
$\mathrm{r}_{\mathrm{m}}$ (mg of HA $/ \mathrm{mg}$ of dyes) & 1.16 & 3.4 & 3.2 & 3.3 & 3.4 & 3.3 \\
\% HA recovered & 0.0 & 58.80 & 57.30 & 56.70 & 65.70 & 65.10 \\
\% Dye elimination & 0.0 & 98.63 & 21.84 & 97.80 & 76.83 & 7.56 \\
4th calcination $\left(\mathrm{r}_{\mathrm{m}} \sim 2\right)$ & & & & & & \\
$\mathrm{r}_{\mathrm{m}}$ (mg of HA $/ \mathrm{mg}$ of dyes) & 0.0 & 2.0 & 1.9 & 1.9 & 2.2 & 2.2 \\
\% HA recovered & 0.0 & 50.00 & 56.40 & 55.30 & 59.10 & 55.80 \\
\% Dye elimination & 0.0 & 91.33 & 21.63 & 96.88 & 75.47 & 7.54 \\
\hline
\end{tabular}




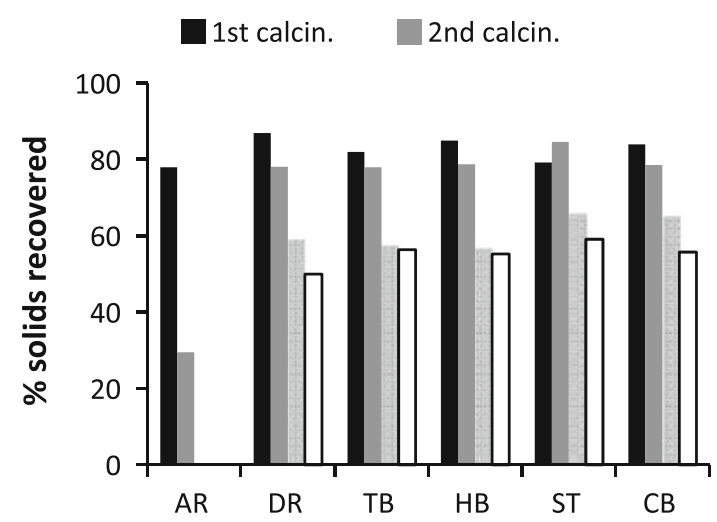

Fig. 2 Percentages of HA solids recovered following consecutive experiments with various dyes

1st calcin. ${ }^{-1}$ 2nd calcin. $\quad$ 3rd calcin. $\square$ 4th calcin.

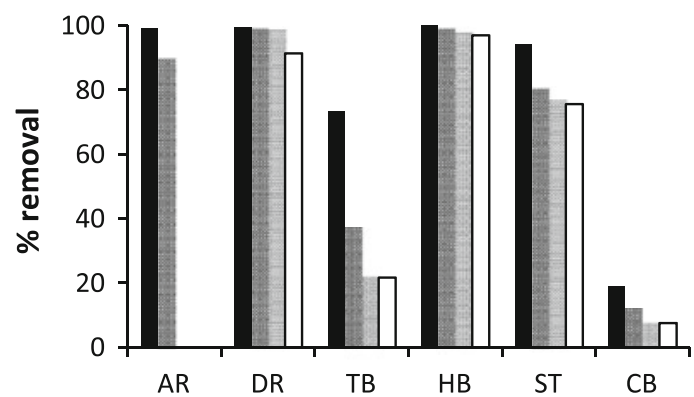

Fig. 3 Percentages of dye removal following consecutive experiments with various adsorbent/dye ratios

particularly well illustrated by the case of Alizarin AR, a known histological stain for calcified tissues. When small $r_{m}$ ratios are used, it is not the calcium phosphate which precipitates out of solution but the calcium-alizarin complex, which results in little calcium phosphate recovery following thermal treatment, unless larger $r_{m}$ ratios are used. This is illustrated in Fig. 4.

Among the dyes considered, Red disperse 167 (DR) and Hydron Blue (HB) were strongly removed. Five successive experiments were run with a large and constant $\mathrm{HA} /$ dye mass ratio of 20 using the recovered HA in each consecutive test, following regeneration. The results are given in Table 4.

After each calcination, the elimination yield was close to $97 \%$ for RD and $99 \%$ for HB. In addition, about 85 and $86 \%$ of calcined apatite was recovered for RD and $\mathrm{HB}$, respectively; therefore, the HA mass loss deduced was respectively 15 and $14 \%$. After ageing overnight, the solution became nearly colourless (elimination yield $\mathrm{E}=97 \%$ ) and a gel residue formed at the bottom of the vessel.

To further investigate the possibility of using this method to treat real industrial waste waters containing dyes and other accompanying additives, genuine textile dye waste water was treated by adding varying amounts of calcium and phosphate ions in order to co-precipitate the dye with the apatite formed. As illustrated in Fig. 5, it was found that a linear relation exists between the measured absorbance at the solution's wavelength of maximum absorption and the amount of calcium introduced. The weight percent of dye removed this way was not calculated because of the simultaneous presence of multiple dyes in this industrial waste water, but the results show that apatite formation in situ eliminates dyes despite the presence of solubilising agents for the dyes. It seems that surface tension modifiers do not affect much the results, which will need to be investigated further.

\section{Conclusion}

Wastewaters contaminated by mixed textile dyes can be treated to eliminate dilute dyes by a precipitation reaction formed near neutral $\mathrm{pH}$ in the presence of calcium and phosphate ions. Following sedimentation or filtration, the co-precipitated dyes and calcium phosphates can be thermally treated to mineralize the organic molecules and
Table 3 Dye removal efficiencies and HA recoveries as a function of adsorbent/dye ratios $\left(r_{m}\right)$ for various dyes after a $6 \mathrm{~h}$ waiting period

\begin{tabular}{llllllll}
\hline Dyes & $\mathrm{r}_{\mathrm{m}}$ & \% HA recovered & \% dye removal & Dyes & $\mathrm{r}_{\mathrm{m}}$ & \% HA recovered & \% Dye removal \\
\hline AR & 5 & 78 & 98.96 & $\mathrm{HB}$ & 5 & 85 & 99.9 \\
& 4 & 63.5 & 98.8 & & 4 & 82 & 99.8 \\
& 3 & 23.3 & 80.0 & & 3 & 73.7 & 99.8 \\
& & & & & 2 & 61.2 & $99 . .8$ \\
DR & 5 & 87 & 99.34 & $\mathrm{ST}$ & 5 & 79.2 & 93.95 \\
& 4 & 78.12 & 99.3 & & 4 & 79.27 & 93.2 \\
& 3 & 73.3 & 99.2 & & 3 & 77.8 & 89.3 \\
& 2 & 65.25 & 99.0 & & 2 & 62.75 & 81.5 \\
TB & 5 & 82 & 73.38 & $\mathrm{CB}$ & 5 & 84 & 18.73 \\
& 4 & 81.12 & 68.1 & & 4 & 75 & 17.4 \\
& 3 & 71.5 & 64.0 & & 3 & 63 & 13.89 \\
& 2 & 68.25 & 51.5 & & 2 & 45.5 & 10.53 \\
\hline
\end{tabular}




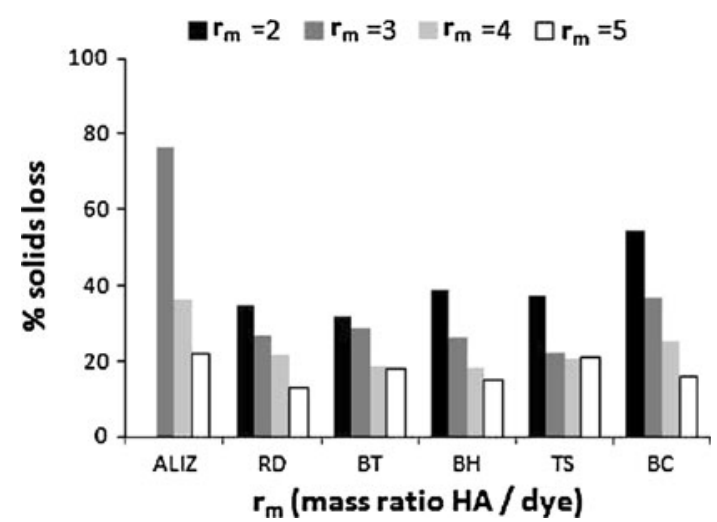

Fig. 4 Loss of adsorbent during co-precipitation with various dyes at different $r_{m}$ ratios

Table 4 Average effectiveness of HA during five cycles of co-precipitation with RD and BH dyes using a 15 min decantation time and constant and large HA/dye mass ratio $r_{m}\left[r_{m}=20 ; C_{\text {dye }}=50 \mathrm{mg} / \mathrm{L}\right.$; $\left.\mathrm{pH}_{\text {solution }}=8.4-8.7\right]$

\begin{tabular}{lll}
\hline Dye & \% Elimination of dye & \% of HA recovered \\
\hline RD & $97.1(0.9)$ & $85.0(2.8)$ \\
BH & $98.6(0.2)$ & $86.3(2.5)$ \\
\hline
\end{tabular}

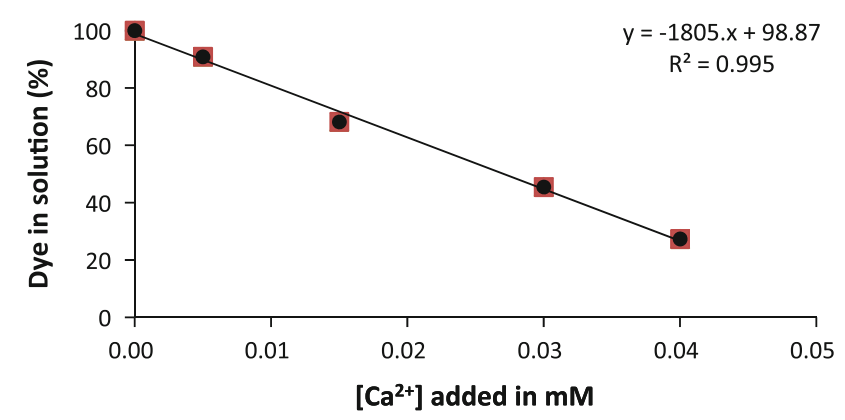

Fig. 5 Decrease in dye absorbance as a function of calcium ion concentration added to precipitate calcium phosphate in the industrial waste-water sample from Bercolor

regenerate the calcium phosphates for further re-use. This makes the treatment process durable and lean in chemical consumptions. Calcium and phosphate salts are inexpensive, and with proper thermal combustion, no other pollution results from the water purification process. This should be an incentive for economically and environmentally concerned operators. In fact, with such a method, the water is purified, the waste is regenerated into new adsorbent and valorized again, with no end of life residues to dispose of.

\section{References}

1. El Ouardi, E., Mrani, M.I., Anoua, M., Chehouani, H.: Optimisation du traitement thermique d'un phosphate application au phosphate du bassin gantour au maroc. Mat. Tech. 97, 133-142 (2009)

2. Gupta, V.K., Jain, R., Varshney, S.: Removal of Reactofix golden yellow 3 RFN from aqueous solution using wheat husk-an agricultural waste. J. Hazard. Mater. 142, 443-448 (2007)

3. Andrzejewska, A., Krysztafkiewicz, A., Jesionowski, T.: Treatment of textile dye wastewater using modified silica. Dyes Pigments 75, 116-124 (2007)

4. Gao, B.Y., Yue, Q.-Y., Wang, Y., Zhou, W.Z.: Color removal from dye-containing waste-water by magnesium chloride. J. Environ. Manag. 82, 167-172 (2007)

5. Hu, Z.J., Xiao, Y., Zhao, D.H., Shen, Y.L., Gao, H.W.: Preparation of dye waste-barium sulfate hybrid adsorbent and application in organic wastewater treatment. J. Hazard. Mater. 175, 179-186 (2010)

6. Gupta, V.K., Mittalc, A., Malviyac, A., Mittalc, J.: Process development for removal and recovery of metanil yellow by adsorption on waste materials-bottom ash and de-oiled soya. J. Hazard. Mater. 151, 834-845 (2008)

7. Gupta, V.K., Mohan, D., Sharma, S., Sharma, M.: Application of low cost adsorbents for dye removal-a review. J. Environ. Manag. 90(8), 2313-2342 (2009)

8. Hasnain Isa, M., Siew Lang, L., Faridah, A.H., et al.: Low cost removal of disperse dyes from aqueous solution using palm ash. Dyes Pigments 74, 446-453 (2007)

9. Wang, S., Wu, H.: Environmental-benign utilisation of fly ash as low-cost adsorbents. J. Hazard. Mater. 136, 482-501 (2006)

10. Pratap Reddy, M., Venugopal, A., Subrahmanyam, M.: Hydroxyapatite photocatalytic degradation of calmagite (an azo dye) in aqueous suspension. Appl. Catal. B Environ. 69, 164-170 (2007)

11. Barka, N., Qourzal, S., Assabbane, A., Nounah, A., Aît-Ichou, Y.: Adsorption of disperse blue SBL dye by synthesized poorly crystalline hydroxylapatite. J. Environ. Sci. 20(10), 1268-1272 (2008) 